\section{LEFT VENTRICULAR DYSFUNCTION AFTER MITRAL VALVE REPAIR: PREDETERMINED OR CAUSED? \\ To the Editor:}

Early mitral valve repair is being done to avoid the delayed left ventricular (LV) damage that happens when repair is performed in larger hearts, as described in the recent article by Quintana and colleagues. ${ }^{1}$ Suri, one of the coauthors of the study of Quintana and colleagues, reported the Mayo Clinic experience showing that LV functional recovery is impaired if LV end-systolic diameter is greater than $36 \mathrm{~mm}^{2}$ The recent report of Quintana and colleagues ${ }^{1}$ analyzed 1705 Mayo Clinic patients with $\mathrm{LV}$ ejection fraction $(\mathrm{EF})$ greater than $60 \%$ and showed that at 4 postoperative days EF was less than $50 \%$ in 1 in 5 patients. LV impairment persisted, with EF returning to a value greater than $60 \%$ in only one-third of patients, versus two-thirds of those with a postoperative $\mathrm{EF}$ greater than $50 \%$. Moreover patients with a postoperative EF less than $40 \%$ had an increased LV end-systolic diameter and a higher hazard of late death. The postoperative LV dysfunction title of Quintana and colleagues ${ }^{1}$ addresses the fallacy of "normal" preoperative myocardial function.

The interpretation of Quintana and colleagues ${ }^{1}$ is that this LV functional finding was predetermined, reflecting a myocardial predisposition toward

\footnotetext{
The Editor welcomes submissions for possible publication in the Letters to the Editor section that consist of commentary on an article published in the Journal or other relevant issues. Authors should: • Include no more than 500 words of text, three authors, and five references. - Type with double-spacing - See http://jtcs.ctsnetjournals.org/misc/ifora.shtm for detailed submission instructions. - Submit the letter electronically via jtcvs.editorialmanager.com. Letters commenting on an article published in the JTCVS will be considered if they are received within 6 weeks of the time the article was published. Authors of the article being commented on will be given an opportunity of offer a timely response ( 2 weeks) to the letter. Authors of letters will be notified that the letter has been received. Unpublished letters cannot be returned.
}

LV deterioration; they could not impugn surgical interventions, which were similar in the groups with and without dysfunction. An alternate hypothesis is that these changes were caused by the surgical intervention of myocardial protection, and that these adverse changes may have been preventable. Quintana and colleagues' report ${ }^{1}$ does not address the methods of protection, and it should.

The capacity of echocardiography to gauge LV end-systolic diameter to guide early intervention was beautifully defined by Suri, ${ }^{2}$ but it also measures how our interventions affect LV size, shape and performance, the nidus of this report. Moreover, another marker of intraoperative damage is septal function, which accounts for half of the LV wall weight. ${ }^{3}$ Reynolds and associates $^{4}$ studied almost 3300 postoperative patients with normal preoperative septal motion and showed that septum paradox (bulging) developed in about $40 \%$; however, they did not report other accepted yardsticks of septal dysfunction, such as mild or severe hypokinesia or akinesia. Septal bulging was thought to be related to surgical ischemia duration.

In contrast, septal damage can be avoided by use of the integrated method of myocardial protection that includes cold antegrade blood cardioplegia, retrograde blood cardioplegia, and a warm reperfusate containing glutamate and aspartate.

The period of clamping in the study of Quintana and colleagues ${ }^{1}$ was only 60 minutes, but our own study in 119 patients showed that septal damage was offset despite ischemia extending to 157 minutes. $^{3}$ Our recent study addressed the septum by means of speckle tracking imaging and showed that septal damage followed only antegrade blood cardioplegia, whereas improved septal function followed the integrated approach ${ }^{5}$ that avoided adverse changes in radial, circumferential, and longitudinal strain.
Quintana and colleagues ${ }^{1}$ should report septal changes.

Findings of LV damage after mitral repair may become problematic in the future, because studies are being planned to compare the mitral clip to surgical correction that addresses the entire mitral apparatus. Catheterbased technology would avoid myocardial damage to paradoxically favor its use, since magnetic resonance imaging studies show no LV dysfunction. ${ }^{6}$ Conversely, LV dysfunction implies problems in myocardial protection that are avoidable with the integrated method or any alternate technique that avoids septal injury.

Gerald D. Buckberg, $M D^{a}$

Constantine L. Athanasuleas, $M D^{b}$

${ }^{a}$ Department of Cardiothoracic Surgery

David Geffen School of Medicine at UCLA

Los Angeles, Calif

${ }^{b}$ Division of Cardiothoracic Surgery University of Alabama at Birmingham Birmingham, Ala

\section{References}

1. Quintana E, Suri RM, Thalji NM, Daly RC, Dearani JA, Burkhart HM, et al. Left ventricular dysfunction after mitral valve repair-the fallacy of "normal" preoperative myocardial function. J Thorac Cardiovasc Surg. 2014;148:2752-62.

2. Suri RM, Schaff HV, Dearani JA, Sundt TM, Daly RC, Mullany CJ, et al. Recovery of left ventricular function after surgical correction of mitral regurgitation caused by leaflet prolapse. J Thorac Cardiovasc Surg. 2009;137:1071-6.

3. Buckberg G, Athanasuleas C, Saleh S. Septal myocardial protection during cardiac surgery for prevention of right ventricular dysfunction. Anadolu Kardiyol Derg. 2008;8(Suppl 2):108-16.

4. Reynolds HR, Tunick PA, Grossi EA, Dilmanian H, Colvin SB, Kronzon I. Paradoxical septal motion after cardiac surgery: a review of 3,292 cases. Clin Cardiol. 2007;30:621-3.

5. Bhaya M, Sudhakar S, Sadat K, Beniwal R, Joshi D, Nanda N, et al. Effects of antegrade vs. integrated blood cardioplegia on left ventricular function evaluated by echocardiographic real-time threedimensional speckle tracking. J Thorac Cardiovasc Surg. 2015;149:877-84.

6. Krumm P, Zuern CS, Wurster TH, Mangold S, Klumpp BD, Henning A, et al. Cardiac magnetic resonance imaging in patients undergoing percutaneous mitral valve repair with the MitraClip system. Clin Res Cardiol. 2014;103:397-404. j.jtcvs.2014.09.066 